\title{
$\mathfrak{B} \mathfrak{o} \mathfrak{\mathfrak { w }} \mathfrak{o} \mathfrak{l} \mathfrak{t}$.
}

S

ie firchlichen Senogungen ber 3eit und befonders bie allge= mein anregende Symbolfrage leitete ganz natürlidi audj sie nidyt

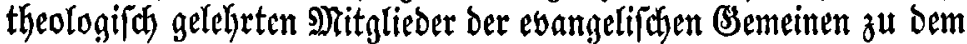

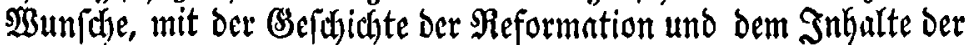
(1)mbolifach Sdiriften nähcr befaunt zu werden.

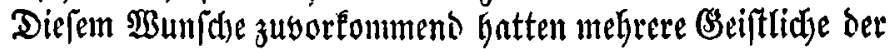
Nriélnigemeine in Berlin wälurend ber legtern Jahre zwifden Pfingften and Beibuachten Des Donnerftags in einer $\mathfrak{A b}_{\text {bend }}=$ ftumbe Borträge für die (Someine in Der Kird)e geljalten und Darin

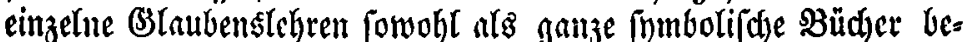

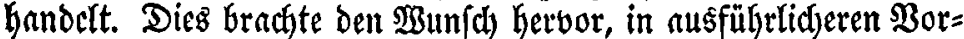
trägen über die (Sefammtgefdjid)te der Meformation und Die Sanpt=

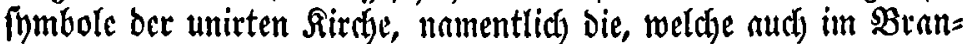
benburgifdyen gegolten lonben oder nodj gelten, näber belebrt ju $^{11}$ werben.

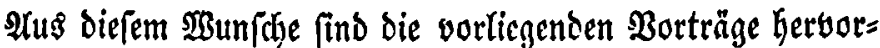
geyangen. Sie wurden in Winter bom Dccembcr 1845 bis 2 wril

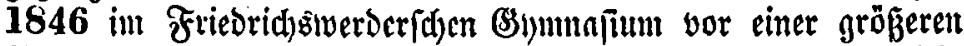
Berfammlung gebilbeter Männer und Frrauen von dem Unterzeich= neten fret gehalten uno gröbltentbeils burdh Sdynealdyreiber nad)= gefobrieben. - So wenig fie nuf tiefere Belehrfamteit 2 nfprud) madjen, tocldje bei bem angegebenen $\mathfrak{B e r b a ̈ l t n i f s ~ n i d j t ~ e r f o r b e r t ~}$ wurbe, möge Darum aud die weniger freng gcoronete Dar|tellung, welche bem mündidfen Bortrage geitattet ift, Entidyuloigung finden.

Meine Alvfidt war nur, ben gebilbeten nicht theologifd ge=

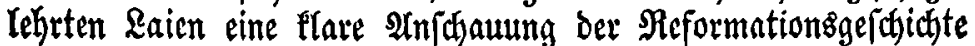
und ber unfer unirten Sirdje befonders widtigen fimbolifdien Srfriften fu geben, dies aber mebr burd) einfache Darlegung ber 


\section{- vi -}

seidichtlidjen Thatfachen als burdy cigente \$etraditungen zu be=

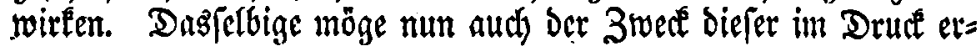
fdheinelloen Borträge fein.

Ess fajien mir widftig neben den bargelegten $2(n$ fidjten audd

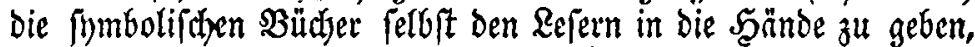

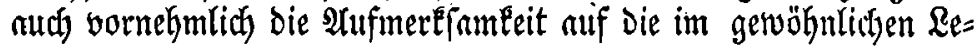

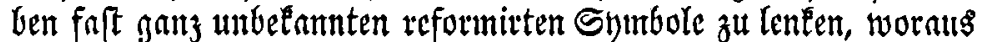

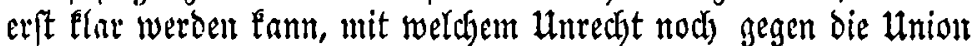
beider (Eonferfīonen amgetïnnft mirb. So habe idy auß̧er Den merl"=

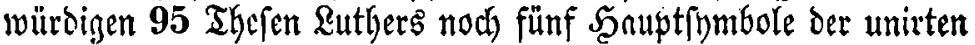

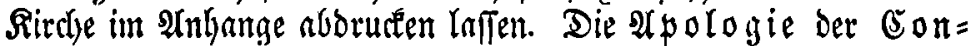

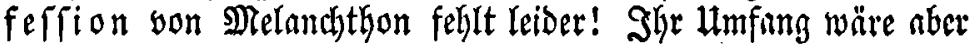

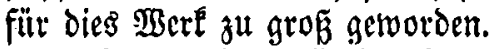

Meinen freundlidyften Danl habe id) Gierbei nod) ëffentlid

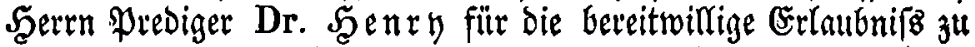
Fagen, meinem Buche bie unter uns nut von $\mathfrak{B e n i g e n ~ g e f a n n t e ~ C o n - ~}$ fessio Gallicana nady feiner trefflidfen beutjdent überfésung bei= geben zu bürfen. Thöge der Segen, weldyen Das Lefen Derfelben gevifis ftiften wirb, ithm Fein freundliches Entgegeneommen recht reidllidy belohnen.

Nöldten nun meine vetergrten 3ugärer und 3uhörerinmen nudy in den gedructeten Borträgen diefelbe Befricoigung finden, wo=

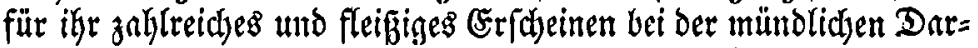

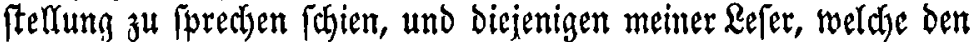

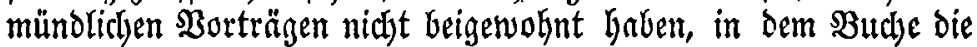

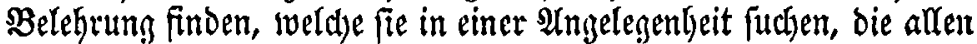

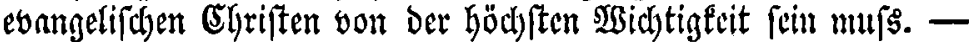
Dann wiro mein \$ud) nidft umfonit gefdrieben fein uno ihm mit Bottes Sällfe und unter feinem reidgen Segen gelingen, woz̆l ts gefendet ift.

Bertin, Den 17 September 1846.

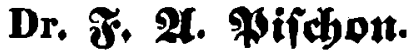

